\title{
Dental skill mix: a cross-sectional analysis of delegation practices between dental and dental hygiene-therapy students involved in team training in the South of England
}

Kristina L Wanyonyi ${ }^{1 *}$, David R Radford ${ }^{2,3}$ and Jennifer E Gallagher ${ }^{1}$

\begin{abstract}
Background: Research suggests that health professionals who have trained together have a better understanding of one another's scope of practice and are thus equipped for teamwork during their professional careers. Dental hygiene-therapists (DHTs) are mid-level providers that can deliver routine care working alongside dentists. This study examines patterns of delegation (selected tasks and patients) by dental students to DHT students training together in an integrated team.
\end{abstract}

Methods: A retrospective sample of patient data $(n=2,063)$ was extracted from a patient management system showing the treatment activities of two student cohorts (dental and DHT) involved in team training in a primary care setting in the South of England over two academic years. The data extracted included key procedures delegated by dental students to DHT students coded by skill-mix of operator (e.g., fissure sealants, restorations, paediatric extractions) and patient demography. $X^{2}$ tests were conducted to investigate the relationship between delegation and patient age group, gender, smoking status, payment-exemption status, and social deprivation.

Results: A total of 2,063 patients managed during this period received treatments that could be undertaken by either student type; in total, they received 14,996 treatment procedures. The treatments most commonly delegated were fissure sealants (90\%) and restorations (51\%); whilst the least delegated were paediatric extractions (2\%). Over half of these patients (55\%) had at least one instance of delegation from a dental to a DHT student. Associations were found between delegation and patient age group and smoking status $(P<0.001)$. Children under 18 years old had a higher level of delegation (86\%) compared with adults of working age (50\%) and patients aged 65 years and over (56\%). A higher proportion of smokers had been delegated compared with non-smokers (45\% cf. 26\%; $P<0.001$ ).

Conclusions: The findings suggest that delegation of care to DHT students training as a team with dental students, involved significantly greater experience in treating children and adult smokers, and providing preventive rather than invasive care in this integrated educational and primary care setting. The implications for their contribution to dentistry and the dental team are discussed, along with recommendations for primary care data recording.

\footnotetext{
* Correspondence: kristina.wanyonyi@kcl.ac.uk

'King's College London Dental Institute, Division of Population and Patient Health, Bessemer Road, London SE5 9RS, UK

Full list of author information is available at the end of the article
} 


\section{Background}

The current position paper of the World Health Organization on scaling up the health workforce considers inter-professional training as an essential step in the development of a collaborative health workforce [1]. In both developed and developing countries, the concept of collaborative practice within the dental team is encouraged, particularly through task sharing and wider use of mid-level dental providers [2-5]. There are several cadres of mid-level dental providers; collectively, they are often referred to as dental care professionals (DCPs) or dental auxiliaries, and include dental hygienists, dental nurses, orthodontic therapists, dental hygiene-therapists, clinical dental technicians, and dental technicians [6].

In recent times, the developing role of dental hygiene and dental therapists has gained wide interest [7-9]. This is because many see potential for improved capacity of dental services through task sharing between dentists and other members of the dental team due to their overlap in skills $[10,11]$. In the UK, there has been a recent move to train dually qualified dental hygiene-therapists [12]. The scope of practice of a dental hygienist is within that of a dental therapist [13], and, when qualified, dental therapists may register and work as a dental hygienist and as a dental therapist. The equivalent personnel who have training to the level of a dental therapist are referred to differently between countries; for example, dental therapists (New Zealand, Malaysia, and USA) [10]; oral health technicians (Brazil) [14]; oral health therapists (Holland) [10]; and dental hygiene-therapists or dental therapists (UK) [6]. The development of their role or scope of practice and the regulation of their practice also vary between countries. These variations mainly revolve around the 'level of autonomy' and 'scope of practice' $[14,15]$. These personnel commonly provide routine care that includes scaling, filling cavities, preventive care, and extraction of children's teeth [16].

In The Netherlands and the UK, the training of hygienists, who mainly work in clinical prevention, has been expanded into dually qualified hygiene-therapists $[10,12]$. In Scandinavian countries, where there are hygienists but no hygiene-therapists, researchers have suggested that the training of hygienists should be expanded to provide them with sufficient skills and the confidence to carry out a greater variety of clinical treatment measures in the future [2]. The rationale behind these changes appears to be to give more time for dentists to cope with increased demand for complex treatments and care for medically compromised patients; these factors are associated with the changing demands and increasingly ageing populations whilst also recognising general improvements in oral health and that some more simple tasks may be delegated to other members of the dental team $[10,17,18]$.
In the UK, the General Dental Council (GDC), as the regulating body, has outlined the roles and responsibilities of all dental professionals, including dental therapists in the GDC 'Scope of Practice' guidance [13], and they have recently approved the concept of 'Direct access' for patients to dental hygienists and dental therapists [19]. This regulation falls in line with other contemporary government policies that have encouraged a team approach to primary dental care services in order to meet the changing demands on dental services [20]. This follows several decades of documents calling for wider use of DCPs, task sharing, and skill mix [21]. Despite such lengthy support, DCPs, particularly those holding a dental therapy qualification, appear to be underutilised [12,15].

Research in the UK to ascertain the reasons for the underutilisation of dental hygiene-therapists has revealed a lack of understanding and misconceptions over their scope of practice amongst dentists [22-26]. Evidence from Brazil suggests that lack of autonomy and credibility with the public has led to challenges in developing the role of oral health technicians [14]. In the USA, whilst dental therapists have developed in many states, they have continued to face opposition from national and state dental associations [27]. In Scandinavia, developing the scope of practice of hygienists also remains an issue of debate [2].

The economic implications of using dental hygienetherapists have also been the subject of debate $[28,29]$. Sun et al. [29] found that although some practices have found ways to incorporate dental hygiene-therapists in their practices, practice principals find it challenging to evaluate their contributions and plan for payments, because there is lack of management information on their productivity.

In regards to acceptability of dental hygiene-therapists, there is evidence that the public and patients in the UK find them acceptable, but knowledge of their roles is unclear and further education of the public is suggested [30,31]. As the number of dental hygienists-therapists in training has expanded, consideration is increasingly being given to developing multi-professional training. Ross et al. [10] suggest that dental students who have been trained together with DCPs have a better understanding of DCP's scope of practice than those who have not. It is therefore important that there is a clear understanding of respective roles of the members of the dental team to further develop skill mix in practice.

As the agenda to promote teamwork, skill mix, and task delegation continues, a clear call for more empirical data on the contribution dental hygiene-therapists make to clinical care has been made [11,29]. Apart from one observational study in primary dental care by Evans et al. [11] in general dental practices in South Wales, little is known about patient delegation within the state funded health system in the UK and there is no published information on what happens when dental and dental 
hygiene-therapy students train together. This study seeks to inform this knowledge gap by contributing findings that will be useful in aiding the understanding of how delegation can work within the dental team in training and analysing data from a patient management system that is common to primary dental care nationally.

This research aimed to examine the activities of a team of dental and dental hygiene-therapy students training together in an integrated team-training primary care environment in the South of England, where barriers to delegation placed by the payment system do not exist. In particular, the analysis focuses on the patterns of delegation of tasks from final year dental students to dental hygiene-therapy students. The dental students, who are under the supervision of tutors, examine and formulate care plans that may involve delegation to dental hygienetherapy students. This is an initial approach to inform a quantitative knowledge gap, using statistical analysis to show magnitude and distribution of delegation and by itself does not answer all questions about delegation, which would include wider elements, features, facilitators, and hindering factors of delegation.

\section{Methods}

The facility at the centre of this research is the University of Portsmouth Dental Academy (UPDA) in the South of England. It is a primary care dental training centre opened in September 2010 to integrate education and training of dental students on outreach training from King's College London with DCPs (dental hygiene-therapy and dental nursing students) training in Portsmouth. The facility was expanded in order to improve both service capacity for the surrounding community and enhance teamwork training in dentistry, having previously only hosted the training of DCPs in any given week, 20 dental students worked three and a half clinical days with $2^{\text {nd }}$ and $3^{\text {rd }}$ year dental hygiene-therapy students (24 per cohort) undertaking two days of clinical work per student.

This research was conducted using retrospective crosssectional patient data obtained from the electronic patient management system at UPDA. The findings presented here form part of a wider body of research that looks into case mix and skill mix at UPDA as well as access to dental care [32]. Ethical Approval was given by NRES Committee Fulham REC: Reference No. 11/LO/1138 Protocol No. NTMHWMOV3 and NHS Portsmouth R\&D Committee Reference No. SSPS/05/11.

The data comprised patient demography and treatment activity in the first 2 years of team training (1 September 2010 to 31 August 2012). Clinical activity included treatment item codes, which indicated the performer of the treatment (dental student or dental hygiene-therapy student). For example, an amalgam restoration would be coded either amalgam restoration for dental student [Amalgam
filling-DS] or amalgam restoration for dental hygienetherapy student [Amalgam filling-HTS], depending on the type of student. This coding structure was part of the patient management software modified by UPDA. Dental students undertook patient assessments and treatment planning including whether or not a treatment should be delegated to a dental hygiene-therapy student, and coded the care accordingly. Dental students had the freedom to delegate tasks within the dental hygiene-therapists scope of practice.

All data on patients who had one or more procedures, labelled by provider of care, were eligible for analysis $(n=2,063)$. These included paediatric tooth extractions (related to disease or exfoliation), restorations, pulpotomies (endodontic treatment on primary teeth), fissure sealants, and urgent care. Other less complex clinical items which may be delegated were not coded by provider of care within the patient management system, most notably scale and polish and fluoride varnish, and thus were not available for skill mix analysis. $X^{2}$ tests were applied to examine the relationship between delegation to dental hygiene-therapy students and patient socio-demographic characteristics; this included patient ethnicity, age, gender, payment status, smoking status, and quintile of deprivation.

Age was analysed in age-groups. First, in three categories 'under 18 years', '18-64 years' (working age adults), and 'over 64 years'. A further analysis of the distribution of delegation by age was undertaken using the 11 National Health Service (NHS) age-groups (0-2 years, $3-5$ years, $6-12$ years, $13-17$ years, $18-24$ years, 25-34 years, 35-44 years, 45-54 years, 55-64 years, 65-74 years, Over 75 years).

Payment status identifies whether a patient is exempt from charges or not within the NHS system, albeit that in this educational setting charges did not apply. Adults of different social circumstances, for example, receiving unemployment benefit, are exempt from payment [33]. All children are automatically exempt from payment in line with the policy in state funded dental care in England; therefore, only adult payment exemption status was analysed in this study. Smoking status and whether a patient was signposted for smoking cessation are automatically collected in the patient management system as clinicians are required to collect this information as part of the payment contract and in support of delivery of preventative care. Quintiles of deprivation were calculated based on the Index of Multiple Deprivation (IMD) score, a measure that provides a relative measure of deprivation at small area level across England [34].

\section{Results}

\section{Patient characteristics and delegation}

There were 2,063 patients and a total of 14,996 treatment procedures in the study data set; $55 \%(1,134)$ of patients had evidence of at least one instance of delegation. There 
were statistically significant relationships between delegation and patient characteristics (Table 1). Younger patients were delegated to dental hygiene-therapy students at a higher rate than other groups $(P<0.001)$, with the majority of patients under the age of 18 years $(86 \%)$ having been delegated at least once, compared with $54 \%$ of older adults ( $\geq 64$ years) and $50 \%$ of working age adults (18-64 years). A higher proportion of smokers had been delegated, compared with non-smokers $(45 \%$ cf. $26 \% ; P<0.001)$. No significant difference was found in the proportion of patients delegated by gender, quintile of deprivation, or payment status.

\section{Patient age and delegation}

The relationship between age and delegation was examined further by 11 age groups (Figure 1), and the findings indicate that a larger proportion of younger patients were delegated compared to older aged patients; this ranged from $100 \%$ of $3-5$ year olds delegated compared to only $44 \%$ of 18-24 year olds. Amongst adult patients, the 35-44 year age-group had the highest level of delegation (55\%).

\section{Treatment type and delegation}

Overall, $46 \%$ of the treatments in the data set analysed were delegated. The procedures most commonly delegated were fissure sealants (90\%), restorations (52\%), and pulpotomies (endodontic treatment on primary teeth) (51\%). The least delegated operations were paediatric tooth extractions (2\%) as outlined in Figure 2. Procedures involving management of soft tissue mucosal lacerations or bleeding, classified as urgent, were performed by dental students.

\section{Discussion}

The findings of this study provide insight into the pattern of delegation from dental students to hygienetherapy students during training, with analysis restricted to the higher level of treatments within the scope of practice of dental hygiene-therapists. The data suggest that, in this educational establishment, $46 \%$ of these higher level treatments and 55\% of patients receiving this care were delegated by the dental students to dental hygienist-therapy students. Overall, dental hygiene-therapy students delivered a higher proportion of preventative tasks and undertook a significantly higher proportion of care on children and adult smokers. The findings do, however, need to be considered within the context, which is a state-funded primary care educational facility in the South of England where patient charges for adults were not applied. Furthermore, it is important to recognise that the findings are an under-representation of the overall clinical

Table 1 Differences in delegation rate by patient socio-demography

\begin{tabular}{|c|c|c|c|c|c|c|}
\hline & Row total & No delegation & & Delegation & & $P$ value \\
\hline & & $\mathrm{n}$ & $\%$ & $\mathrm{n}$ & $\%$ & \\
\hline Delegation Overall & 2,063 & 929 & 45.0 & 1,134 & 55.0 & \\
\hline \multicolumn{7}{|l|}{ Gender } \\
\hline Female & 926 & 419 & 45.2 & 507 & 54.8 & 0.447 \\
\hline Male & 1,137 & 510 & 44.9 & 627 & 55.1 & \\
\hline \multicolumn{7}{|c|}{ Payment status (adults only; $n=1,740$ ) } \\
\hline Non-exempt & 1,569 & 793 & 50.5 & 776 & 49.5 & \\
\hline Exempt & 171 & 83 & 48.5 & 88 & 51.5 & 0.630 \\
\hline \multicolumn{7}{|l|}{ Age groups } \\
\hline Under 18 years & 282 & 41 & 14.5 & 241 & 85.5 & $0.001^{*}$ \\
\hline Working age (18-64 years) & 1,567 & 789 & 50.4 & 778 & 49.6 & \\
\hline Over 64 years & 214 & 99 & 46.3 & 207 & 53.7 & \\
\hline \multicolumn{7}{|c|}{ Quintiles of deprivation based on patient population $(n=2,043)$} \\
\hline Most deprived 1 & 445 & 200 & 44.9 & 245 & 55.1 & 0.988 \\
\hline 2 & 423 & 192 & 45.4 & 231 & 54.6 & \\
\hline 3 & 483 & 222 & 46.0 & 261 & 54.0 & \\
\hline 4 & 450 & 199 & 44.2 & 251 & 55.8 & \\
\hline Least deprived 5 & 241 & 108 & 44.6 & 134 & 55.4 & \\
\hline \multicolumn{7}{|c|}{ Smoking cessation signposting (adults only; $n=541$ ) } \\
\hline No & 196 & 145 & 74.0 & 51 & 26.0 & $0.001^{*}$ \\
\hline Yes & 345 & 191 & 55.4 & 154 & 44.6 & \\
\hline
\end{tabular}

*Statistically significant differences in bold*; $n=2,063$ unless otherwise stated. 


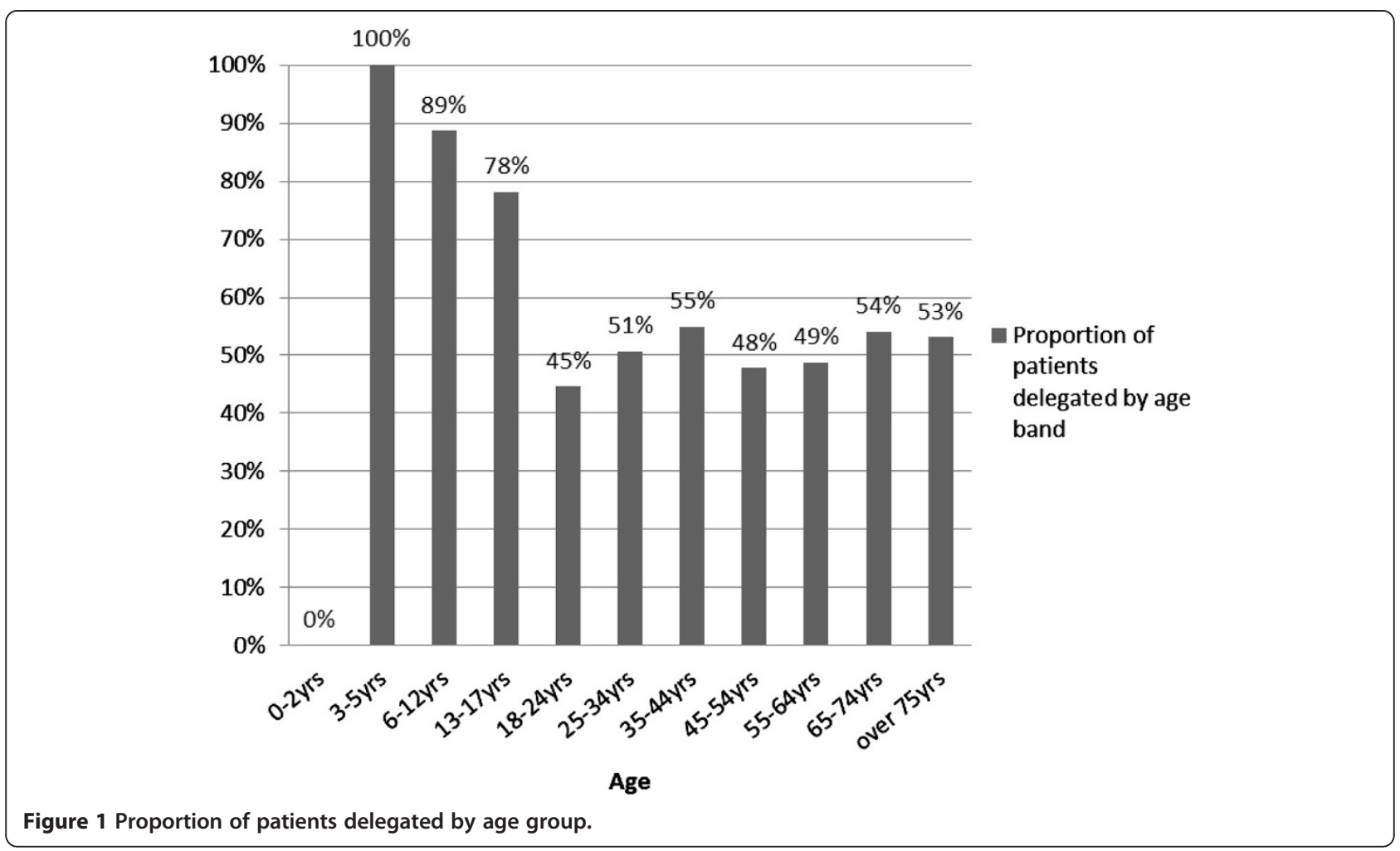

care provided by the dental hygienist-therapists students, as some simple elements of care were not coded by skill mix and attributed to them in the management system.

The high rate of delegation of children (86\%) compared with adults ( $50 \%$ of $18-64$ years old and $54 \%$ of $\geq 65$ years old) could be attributed to a number of factors. First, the more widely accepted and traditional role of the dental hygiene-therapist in children's care; since the first dental therapists were introduced to work in school dental services in New Zealand [35] the perception that those with

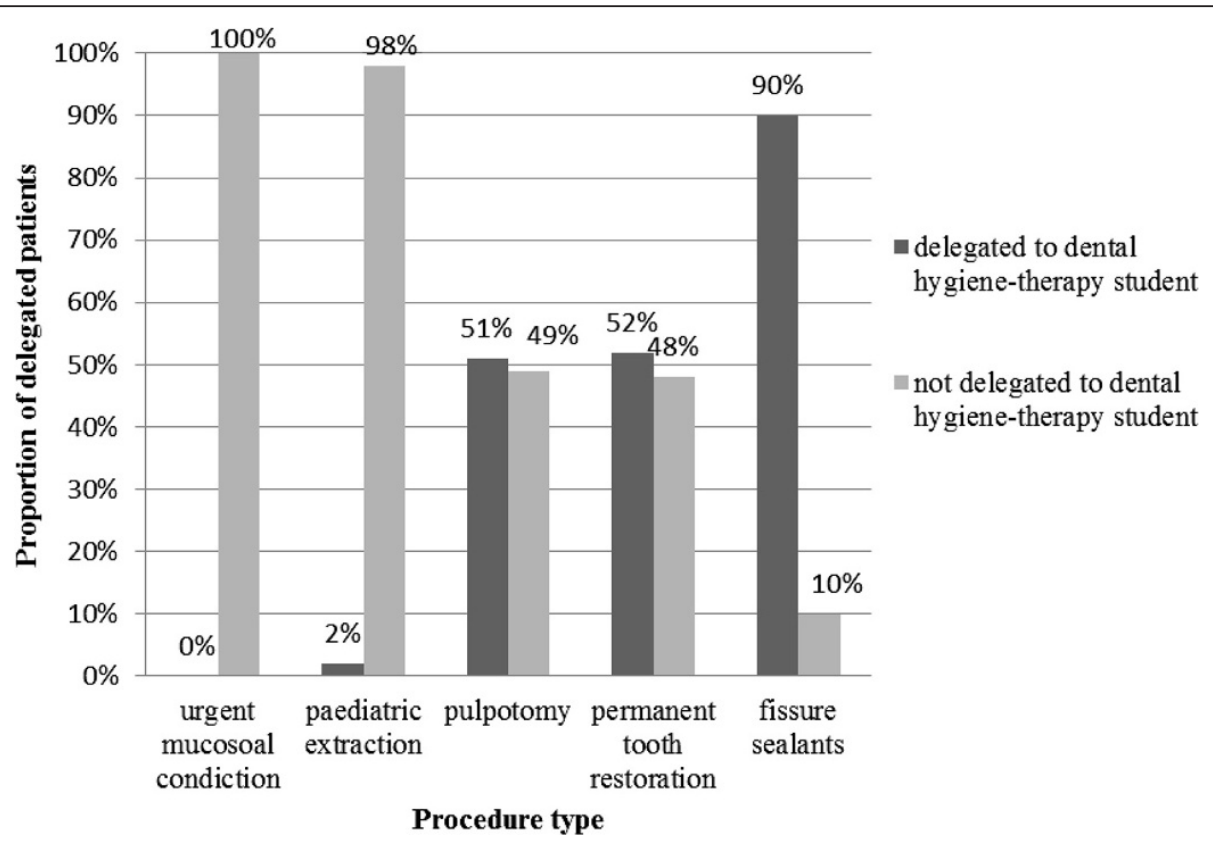

Figure 2 Rate of treatment delegation from dental students to hygiene-therapy students. 
therapy training are well suited to caring for children has persisted. Second, given this is an educational establishment, the need for students to gain certain clinical experience undoubtedly plays a role; dental hygiene-therapy students only have the opportunity to treat children at UPDA, whilst dental students do so in other settings. The findings, therefore, demonstrate that hygiene-therapists gain experience in children's care. This is important as they move forward in their careers as various studies suggest there are gains to be made in patient outcomes and productivity through their utilisation in children's care $[36,37]$.

Moving on to the rationale for the delegation rate of adult care, the lower level of delegation amongst adults may be attributed to a number of factors. First, 'scale and polish', a common component of adult care, was not coded by provider of care and therefore could not be included in the analysis. This may have reduced the potential for a large number of adult patients who had been delegated for that procedure from being included in the analysis. Second, adult patients may have required more complex overall care, therefore necessitating the additional knowledge and skills of a dentist. Third, dental students at this level need experience of more complex procedures, e.g., endodontic treatment, fixed and removable prosthodontics, and so may be more selective in focusing their clinical time on complex tasks required by patients and delegating routine care.

This patient management system data revealed that preventative care which was well within the scope of a dental hygiene-therapist was delegated at a higher rate than restorative tasks. While still considering prevention, it is noteworthy that the contribution of dental hygienetherapists to health promotion, including clinical prevention, is considered vital for contemporary evidence-based care [38,39]; this includes items such as fissure sealants [40]. Furthermore, the experience gained by these students in prevention programmes, therefore, places them in an ideal position to participate in prevention, particularly as policy makers in England are placing greater emphasis on targeted public health programmes [41] and clinical prevention [42]. In countries such as Brazil, oral health technicians, with a similar scope of practice, have found an invaluable place in the provision of public health programmes [14].

These findings suggest that a significantly higher proportion of smokers than non-smokers were delegated to dental hygiene-therapists for clinical treatment. According to the system of practice at UPDA, patients identified as smokers are signposted to smoking cessation services. Dental team members do not provide specific smoking cessation counselling nor are they able to prescribe aids to cessation such as nicotine replacement therapy, etc. The fact that a large number of smokers are treated by dental hygiene-therapy students highlights opportunities for health messages, including more specific smoking cessation support, and thus contributes to the management of common risk factors [43]. Evidence from the US, UK, and Australia suggests that dental hygienists and dental hygiene-therapists can successfully play a role in providing smoking cessation counselling [44-46].

This analysis reveals vital information on the delegation pattern for a range of restorative tasks, which are within dental therapists' scope of practice, but notably are not as widely performed once qualified $[47,48]$. The findings compare broadly with those of Evans et al. [11], who suggest that a significant amount of care $(35 \%$ of care visits and $43 \%$ of clinical time) could be delivered by trained dental hygienists and therapists. However, there is evidence that qualified dental hygiene-therapists in the UK undertake more simple hygiene than therapy work, which is a possible concern as it may lead to deskilling [48]. It is worth noting that dental hygienetherapists' scope of practice supports their working in either role allowing them to deliver both routine restorative work and periodontal care to adults [13], as well as prevention.

This study focused on the recorded clinical experiences gained by both dental students and dental hygienetherapists when trained together, and thus provides insight into their preparation for future practice. Although the study has limitations due to the inability to analyse total procedures delegated in the 2 year period, it does provide clear quantitative insight to a model of skill mix. Furthermore, this is an educational facility where curricula and learning may play a part in determining who provides what care in the dental team; however, the possibility that these early professional behaviours may influence future professional working patterns should be considered. For the educational facilities, the knowledge of the range and type of patients treated by dental hygiene-therapists, especially risk groups such as smokers, is useful in planning training of the students in health promotion.

Further research is required to understand when and why students in training delegate or refer on particular treatments or patient groups. There is also room to explore how different models of skill mix and delegation rate relate to demand for care.

As mentioned above, one limitation of this study was that not all care was coded by the provider in the patient management system and thus limited the analysis; therefore, it is recommended that all primary care patient management systems should apply codes to indicate which type of operator provided care, so that a greater understanding of skill mix can be gained. This small change would provide additional insight to primary dental care working practices, both current and future. 


\section{Conclusions}

The findings suggest that delegation of care to dental hygiene-therapy students in team training with dental students, involved significantly more experience in treating children and adult smokers, and providing preventive rather than invasive care during their clinical training in an integrated educational and primary care service. Educators and planners of dental services seeking to improve and understand the use of dental team skill mix, should consider coding all treatment items in patient management systems, by type of operator, in order to facilitate a wider understanding of the clinical experience and productivity of different members of the dental team in the provision of patient care.

\section{Abbreviations \\ DCPS: Dental care professionals; GDC: General Dental Council; NHS: National Health Service; UPDA: University of Portsmouth Dental Academy; DHT: dental hygiene- therapy. \\ Competing interests \\ DRR is Director of Clinical Studies for the Dental Students at UPDA, whilst JEG leads Dental Public Health teaching across the Institute and KLW contributes to the undergraduate dental teaching programme.}

\section{Authors' contributions}

KLW participated in study design, conducted the research, and prepared the manuscript. DRR was involved in the research coordination and contributed to the manuscript. JEG participated in the study design, supervised the research, and contributed to the manuscript. All authors read and approved the final manuscript.

\section{Acknowledgements}

This research was made possible by the support of a PhD studentship from King's College London Dental Institute and University of Portsmouth Dental Academy. Ethical Approval was given by NRES Committee Fulham REC: Reference No: 11/LO/1138 Protocol No- NTMHWMOV3 and NHS Portsmouth R\&D Committee HIOW Shared RM \& G Services RM \& G Reference No: SSPS/05/11. We would also like to acknowledge Professor Sara Holmes and Mrs Sophie Dampier for their support and facilitating this research.

\section{Author details \\ 'King's College London Dental Institute, Division of Population and Patient Health, Bessemer Road, London SE5 9RS, UK. 'Teaching Division, King's College London Dental Institute, Guys Tower, Guys Hospital, St Thomas Street, London SE1 9RT, UK. ${ }^{3}$ University of Portsmouth Dental Academy, William Beatty Building, Hampshire Terrace, Portsmouth, Hampshire PO1 2QG, UK.}

Received: 23 May 2014 Accepted: 25 September 2014 Published: 18 November 2014

\section{References}

1. World Health Organisation: Transforming and Scaling Up Health Professionals' Education and Training: WHO Education Guidelines 2013. [http://apps.who.int/ iris/bitstream/10665/93635/1/9789241506502_eng.pdf]

2. Virtanen Jl, Tseveenjav B, Wang NJ, Widström E: Nordic dental hygienists' willingness to perform new treatment measures: barriers and facilitators they encounter. Scand J Caring Sci 2011, 25:311-316.

3. Naughton DK: Expanding oral care opportunities: direct access care provided by dental hygienists in the United States. J Evid Based Dental Practice 2014, 14:171-182.

4. Achembong LN, Ashu AM, Hagopian A, Downer A, Barnhart S: Cameroon mid-level providers offer a promising public health dentistry model. Human Resour Health 2012, 10:1478-4491.

5. Luciak-Donsberger C: Origins and benefits of dental hygiene practice in Europe. Int J Dent Hyg 2003, 1:29-42.
6. Gallagher J: Dental professionals. In Encyclopedia of Public Health. $12^{\text {th }}$ edition. Edited by Heggenhougen K, Quah S. San Diego: Elsevier; 2008:126-136.

7. Nash DA, Friedman JW, Mathu-Muju KR, Robinson PG, Satur J, Moffat S, Kardos R, Lo ECM, Wong AHH, Jaafar N, van den Heuvel J, Phantumvanit P, Chu EO, Naidu R, Naidoo L, McKenzie I, Fernando E: A review of the global literature on dental therapists. Community Dent Oral Epidemiol 2014, 42:1-10.

8. Rowbotham JS, Godson JH, Williams SA, Csikar Jl, Bradley S: Dental therapy in the United Kingdom: part 1. Developments in therapists' training and role. Br Dent J 2009, 207:355-359.

9. Moffat S, Coates D: Attitudes of New Zealand dentists, dental specialists and dental students towards employing dual-trained Oral Health graduates. Br Dent J 2011, 211:E16-E16.

10. Nash DA, Friedman JW, Kardos TB, Kardos RL, Schwarz E, Satur J, Berg DG, Nasruddin J, Mumghamba EG, Davenport ES, Nagel R: Dental therapists: a global perspective. Int Dent J 2008, 58:61-70.

11. Evans C, Chestnutt IG, Chadwick BL: The potential for delegation of clinical care in general dental practice. Br Dent J 2007, 203:695-699.

12. Ross MK, Ibbetson RJ, Turner S: The acceptability of dually qualified dental hygienist-therapists to general dental practitioners in South-East Scotland. Br Dent J 2007, 202:E8.

13. General Dental Council: The Scope of Practice. London: General Dental Council; 2013.

14. Sanglard-Oliveira C, Werneck MA, Lucas S, Abreu MHNG: Exploring professionalization among Brazilian oral health technicians. Hum Resour Health 2012, 10:5

15. Turner S, Ross MK, Ibbetson RJ: Dental hygienists and therapists: how much professional autonomy do they have? How much do they want? Results from a UK survey. Br Dent J 2011, 210:E16-E16.

16. Friedman JW: The international dental therapist: history and current status. J California Dental Assoc 2011, 39:23-29.

17. Gallagher JE, Wilson NHF: The Future Dental Workforce? Br Dent J 2009, 206:195-199.

18. Gallagher J, Kleinman E, Harper P: Modelling workforce skill-mix: how can dental professionals meet the needs and demands of older people in England? Br Dent J 2010, 208:E6. Discussion 116-117.

19. General Dental Council: Guidance on Direct Access. London: General Dental Council; 2013.

20. Department of Health: Liberating the NHS: Developing the Healthcare Workforce from Design to Delivery. ; 2012 [https://www.gov.uk/government/ uploads/system/uploads/attachment_data/file/216421/dh_132087.pdf]

21. Smith NJ: The education and training of personnel auxiliary to dentistry. Br Dent J 1993, 175(6):193-195.

22. Douglass CW, Lipscomb J: Expanded function dental auxiliaries: potentia for the supply of dental services in a national dental program. J Dent Educ 1979, 43:556-567.

23. Hay IS, Batchelor PA: The future-role of dental therapists in the UK - a survey of district dental officers and general-practitioners in England and Wales. Br Dent J 1993, 175:61-66.

24. Ireland RS: Dental therapists: their future role in the dental team. Dental Update 1997, 24:269.

25. Gallagher J, Wright D: General dental practitioners' knowledge of and attitude towards the employment of dental therapist in general practice. Br Dent J 2002, 194:37-41.

26. Ward $P$ : The changing skill mix - experiences on the introduction of the dental therapist into general dental practice. Br Dent J 2006, 200:193-197.

27. Friedman JW, Mathu-Muju KR: Dental therapists: improving access to oral health care for underserved children. Am J Public Health 2014, 104:1005-1009.

28. Sun N, Harris RV: Models of practice organisation using dental therapists: English case studies. Br Dent J 2011, 211:E6-E6.

29. Harris RV, Sun N: Translation of remuneration arrangements into incentives to delegate to English dental therapists. Health Policy 2012, 104:253-259.

30. Dyer TA, Humphris G, Robinson PG: Public awareness and social acceptability of dental therapists. Br Dent J 2010, 208:E2.

31. Dyer TA, Robinson PG: Exploring the social acceptability of skill-mix in dentistry. Int Dent J 2008, 58:173-180.

32. Wanyonyi KL, Radford DR, Gallagher JE: The relationship between access to and use of dental services following expansion of a primary care service to embrace dental team training. Public Health 2013, 127:1028-1033.

33. NHS Choices: Who is Entitled to Free NHS Dental Treatment in England? [http://www.nhs.uk/chq/Pages/1786.aspx?CategorylD =74] 
34. Department for Communities and Local Government: The English Indices of Deprivation 2010; [https:/www.gov.uk/government/statistics/english-indicesof-deprivation-2010]

35. Kravitz SA, Treasure ET: Utilization of dental auxiliaries - attitudinal review from six developed countries. Int Dent J 2007, 57:267-273.

36. Bailit HL, Beazoglou TJ, DeVitto J, McGowan T, Myne-Joslin V: Impact of dental therapists on productivity and finances: I. Literature review. J Dental Education 2012, 76:1061-1067.

37. Wang NJ: Use of dental hygienists and returns to scale in child dental care in Norway. Community Dent Oral Epidemiol 1994, 22:409-414.

38. Dyer TA, Robinson PG: General health promotion in general dental practice - The involvement of the dental team Part 2: A qualitative and quantitative investigation of the views of practice principals in South Yorkshire. Br Dent J 2006, 201:45-51.

39. Baltutis $L M$, Gussy MG, Morgan MV: The role of the dental hygienist in the public health sector; an Australian perspective. Int Dent J 2000, 50:29-35.

40. Nilchian F, Rodd H, Robinson P: Influences on dentists decisions to refer paediatric patients to dental hygienists and therapists for fissure sealants: a qualitative approach. Br Dent J 2009, 207:E13.

41. Public Health England: Local authorities improving oral health: commissioning better oral health for children and young people. In London: Public Health England; 2014. https://www.gov.uk/government/uploads/system/ uploads/attachment_data/file/321503/CBOHMaindocumentJUNE2014.pdf.

42. Public Health England, Department of Health and British Association for the study of community dentistry: Delivering better oral health: An evidence-based toolkit for prevention. In $3^{\text {rd }}$ edition. London: Public Health England; 2014. https://www.gov.uk/government/uploads/system/ uploads/attachment_data/file/357835/DBOHv3SEP2014MainDocument.pdf.

43. Petersen PE, Yamamoto T: Improving the oral health of older people: the approach of the WHO Global Oral Health Programme. Community Dent Oral Epidemiol 2005, 33:81-92.

44. Gordon JS, Andrews JA, Crews KM, Paayne TJ, Severson HH: The 5A's vs. $3 A^{\prime}$ s plus proactive quitline referral in private practice dental offices: preliminary results. Tob Control 2007, 6:285-288

45. Matias MA, Steindl SR, Plonka KA, Pukkallus M, Palmer J, Holcombe T, Seymour GJ, Marshall Rl: Do school based anti-smoking campaigns delivered by oral health therapists work? Aust Dent J 2013, 58:301-305.

46. Pau A, Olley RC, Murray S, Chana B, Gallagher J: Dental hygienists' self-reported performance of tobacco cessation activities. Oral Health \& Preventive Dentistry 2011, 9:29-36.

47. Jones $G$, Devalia R, Hunter $L$ : Attitudes of general dental practitioners in Wales towards employing dental hygienist-therapists. Br Dent $J$ 2007, 203:E19.

48. Godson JH, Williams SA, Csikar Jl, Bradley S, Rowbotham JS: Dental therapy in the United Kingdom: part 2. A survey of reported working practices. Br Dent J 2009, 207:417-423.

doi:10.1186/1478-4491-12-65

Cite this article as: Wanyonyi et al: Dental skill mix: a cross-sectional analysis of delegation practices between dental and dental hygiene-therapy students involved in team training in the South of England. Human Resources for Health 2014 12:65.

\section{Submit your next manuscript to BioMed Central and take full advantage of:}

- Convenient online submission

- Thorough peer review

- No space constraints or color figure charges

- Immediate publication on acceptance

- Inclusion in PubMed, CAS, Scopus and Google Scholar

- Research which is freely available for redistribution

Submit your manuscript at www.biomedcentral.com/submit
C Biomed Central 